\title{
The effects of situation variability in a simulation-based training for implicit innovation knowledge
}

\author{
Saar Van Lysebetten (Corresponding Author) \\ Ghent University, Belgium \\ Saar.VanLysebetten@UGent.be
}

Frederik Anseel

UNSW Business School, UNSW Sydney, Australia

f.anseel@unsw.edu.au

\section{Diana R. Sanchez}

San Francisco State University, USA

sanchezdianar@sfsu.edu

This is an uncorrected pre-print (before peer review) version of a forthcoming article in Simulation \& Gaming. Please cite as:

Van Lysebetten, S., Anseel, F., \& Sanchez, D.R. (2020). The effects of situation variability in a simulation-based training for implicit innovation knowledge. Simulation \& Gaming. https://doi.org/10.1177/1046878120914327

Acknowledgment: This study was part of the Baekeland project 140760, funded by Agentschap Innovatie en Ondernemen (IWT) and by CREAX and Innduce.me. We thank CREAX for its generous and continued support in completing this research project. 


\begin{abstract}
Background. During the last decades, the use of simulations for training purposes has sparked wide interest. However, it is unclear how training format characteristics may affect learning, resulting in a lack of evidence-based guidelines for training developers and organizations.
\end{abstract}

Aim. We explore to what extent variation in the situations presented during a simulation training may improve learning outcomes. We test this research question in the context of a simulation-based training for improving innovation knowledge.

Methods. A sample of 131 business students was invited to participate in a study with a pretest and two posttests (within 48 hours after and 4 weeks later) and three conditions: a control group without training, an experimental training group with low situational variation, and an experimental training group with high situational variation.

Results and Conclusion. Compared to the control group, high but not low situational variation improved innovation knowledge. Participants' prior innovation knowledge did not moderate the results. Hence, our findings indicate that ideally a simulation training includes multiple situations that offer learners various opportunities to practice innovation challenges.

Keywords: innovation knowledge, leaning outcomes, simulation-based training, situation variation 


\section{Background}

A growing body of evidence suggests that simulation-based training can be effective for a variety of learning outcomes, sometimes outperforming traditional methods (Gegenfurtner, QuesadaPallares, \& Knogler, 2014; Sitzmann, 2011; Vogel et al., 2006). Simulations are often considered more appealing and engaging than traditional learning settings such as classroom lectures or textbooks materials, leading to higher completion rates (Liaw, 2008; Ong \& Lai, 2006). As a result, simulationbased training has become a popular method to improve cognitive outcomes (Anderson \& Lawton, 2009; Mayer, Dale, Fraccastoro, \& Moss, 2011; Rogers, 2011; Scherpereel, 2005).

Researchers have focused on design characteristics to maximize the learning effectiveness of simulation-based training (Bedwell, Pavlas, Heyne, Lazzara, \& Salas, 2012; Garris, Ahlers, \& Driskell, 2002; Rutten, Van Joolingen \& Van der Veen, 2012; Sitzmann, 2011; Sanchez \& Van Lysebetten, 2017; Wilson et al., 2009). Some design characteristics have been connected to learning effectiveness, such as learner control (Landers \& Reddock, 2017), multimedia elements (Gegenfurtner et al., 2014), or engagement with training materials (Sitzmann, 2011).

One design characteristic that remains underexplored is situational variation. In simulationbased training learners are presented with challenging situations to consider and respond to. Variation in these situations typically comes from differences in their surface characteristics, while still focusing on the same underlying learning principles (Lievens \& Anseel, 2007). To date, situational variation has remained largely unexplored in simulation-based training research. While some scholars have suggested that presenting multiple situations might improve learning (van Merriënboer, Kester, \& Paas, 2006), it is unclear how much variation would benefit learning. Understanding the impact of situational variation on learning effectiveness could explain some of the different effects reported in the simulation-based training literature (Sanchez \& Van Lysebetten, 2017). Adding situational variation could provide a simple, cost-effective strategy for organizations, but this necessitates research-based guidance on how much variation is effective. Therefore, the aim of the current paper is to examine the effects of low versus high levels of situation variation in a simulation-based training on performance on an innovation knowledge test. 


\section{Simulation-Based Training for Innovation Outcomes}

Given variations in how simulations are defined in the research literature (Cannon-Bowers \& Bowers, 2009; Garris, Ahlers, \& Driskell, 2002; Sitzmann, 2011) we clarify our definition of simulation-based training as formats that involve instructions and situations based in reality and delivered through a computer (Bell, Kanar, \& Kozlowski, 2008). Increased popularity of simulationbased training (Cannon-Bowers, Bowers, \& Procci, 2010; Gegenfurtner et al., 2014; Mayer, 2011; Training Industry Report, 2017) has been fostered by their potential to enhance learner motivation and the learning process (Bell et al., 2008; Sitzmann, 2011). The realistic virtual environments of simulation-based training can be perceived as fun, attractive, and approachable by learners, making learning goals more intrinsically motivating (Malone, 1981; Vogel et al., 2006). Given learner's openness to simulations, many may experience higher self-efficacy because they feel capable repeating and performing tasks in a low stakes environment until their skills are satisfactory (Bandura, 1977; Tennyson \& Jorczak, 2008). Meta-analyses have demonstrated that simulation-based trainings can stimulate self-efficacy, motivation, and learning (Gegenfurtner et al., 2014; Sitzmann, 2011).

Several practical advantages of simulation-based training have contributed to its rising popularity. For instance, a trainer's presence is not always required because the training is delivered from a computer and learners may have flexibility to complete the training at a time and place that is convenient for them (Bell et al, 2008; Sun, Tsai, Finger, Chen, \& Yeh, 2008). In addition, simulation training can be designed to be customizable to individual preferences such as pausing or adjusting the pacing of a training that can be controlled by a user in a simulation (Bouhnik \& Marcus, 2006; Landers \& Reddock, 2017). The customizability of simulations can be further beneficial when designing rare events on the job that are harder to train, such as implicit knowledge about the innovation process (Cannon-Bowers \& Bowers, 2009).

Simulation-based training has been researched across domains and for various cognitive outcomes including decision making for military commanders (Beal \& Christ, 2004), clinical reasoning for medical doctors making diagnoses (Consorti, Mancuso, Nocioni, \& Piccolo, 2012), and critical thinking skills and mental models for business students learning to manage organizations (Lovelace, Eggers, \& Dyck, 2016; Palmunen, Pelto, Paalumäki, \& Lainema, 2013; Scherpereel, 
2005). These studies suggest that participating in simulation-based training can improve cognitive skills, understanding one's environment, decision making, and performance. Given these and other positive findings that utilized simulation training for complex cognitive skills (Lainema \& Nurmi, 2006; Siewiorek, Gegenfurtner, Lainema, Saarinen, \& Lehtinen, 2013), we will analyze advancements in implicit innovation knowledge using a simulation training.

Across research it has been established that innovation is a crucial source of organizational success (Anderson, De Dreu, \& Nijstad, 2004; Anderson, Potočnik, \& Zhou, 2014), which has allowed innovation to be widely pursued (Yuan \& Woodman, 2010). One approach to improving innovation is to stimulate employees' innovation potential where employees are actively involved in the ideas, actions, and decisions that may produce innovative solutions (Scott \& Bruce, 1994). Much research has been devoted towards enhancing employee-driven innovation (Anderson et al., 2014; Birdi, Leach, \& Magadley, 2016). However, the impact cognitive factors have on innovation and how to advance implicit knowledge and underlying knowledge structures (e.g., schemas, mental models, cognitive frameworks) of innovation, have been neglected in research (Anderson et al., 2014; Birdi et al., 2016). This is a relevant topic to pursue in research given evidence that suggests an individual's effective decision making and performance is associated with accurate knowledge structures and insights in key principles of that domain (Chi, Feltovich, \& Glaser, 1981; Dane, Rockmann, \& Pratt, 2012; Gary \& Wood, 2011; Gavetti \& Levinthal, 2000).

When individuals encounter situations, they form mental representations of these experiences (Gentner \& Stevens, 1983). In these mental representations, individuals can generate inferences and manipulate analogies, which helps them to develop implicit knowledge and connect this knowledge into a broader cognitive map of knowledge structures (i.e., mental models; Gary \& Wood, 2011; Johnson-Laird, 1983). Studies have shown that knowledge structures help individuals understand causal relationships between contributory factors and situation outcomes. It could be assumed that accurate cognitive frameworks of the innovation domain may provide resources for individuals to overcome innovation challenges and may guide individuals in their decision-making during innovation projects. These knowledge structures may lead to better approaches and individual performance when confronted with complex innovation projects. Given the sparse research on 
advancing implicit innovation knowledge (Dane \& Pratt, 2007), there is no practical guidance on selecting and designing effective learning environments for this purpose. This study aims to identify effective training formats for implicit innovation knowledge to guide the design of future trainings.

\section{Hypotheses and research questions}

As a baseline hypothesis, we first test whether the simulation training has a main effect on the targeted outcome, performance on an innovation knowledge test. Because there are compelling arguments for positive and negative effects of including more variation in simulation tests, we articulated competing hypotheses for variation:

Hypothesis 1. Learners in a simulation training for innovation will have better innovation knowledge than learners who receive no training.

Working memory (i.e., the cognitive system that allows individuals to retain and process information; Baddeley, 2003) has a limited capacity (Baddeley, 1992; Cowan, 2001). The mental activity demanded from working memory is defined as cognitive load (van Gog, Paas, \& Sweller, 2010). When this limited capacity of working memory is reached there is cognitive overload and the individual is not able to concentrate or focus, leading to an inability to process relevant information, integrate new and prior knowledge, and hindering learning (Gathercole \& Alloway, 2012).

Cognitive load theory suggests that training design should reduce cognitive load and the demands placed on working memory (Paas, Renkl, \& Sweller, 2003). To this end, a training should; (a) find an optimal level of complexity and difficulty in the materials (i.e., intrinsic load), (b) reduce factors that do not facilitate learning such as distracting and unnecessary stimuli (i.e., extraneous load), and (c) support cognitive load for relevant learning materials involved with mental model formation (i.e., germane load). This, simulation design should optimize intrinsic load and germane load and minimize extraneous load.

Offering a variety of situations in a simulation may induce germane load and stimulate the learning processes necessary for cognitive learning (i.e., mental model acquisition). When a learner resolves different versions of the same task, the learner will receive more opportunity to practice and to apply the cognitive processes of selecting, organizing, and integrating relevant information into the knowledge structures, which implies deep cognitive learning. Situational variations also provide more 
opportunity to detect common principles and similarities across different situations, distinguish relevant information from irrelevant cues, and identify the range of situations in which the principles can be applied (Anderson, 1982; Van Gerven, Paas, \& van Merriënboer, 2006). Higher situational variation may give leaners more opportunities to integrate the underlying structures, insights, and principles into richer and accurate mental models, which drive learning. Thus, on one hand, we hypothesize:

Hypothesis 2a. A high level of situational variation in a simulation-based training will lead to more innovation knowledge compared to a low level of situational variation.

However, from a cognitive load perspective, it can be argued that training is more complex when there is more situational variation because the learner must process more information. Greater complexity induces a higher intrinsic load, which requires more mental activity from the learner's working memory. Since the working memory has a limited capability to process information (Baddeley, 1992; Cook, 2006), too much situational variation could result in cognitive overload (i.e., with high intrinsic load, the training becomes too complex for the learner). This could undermine training effectiveness because the learner might become unable to concentrate and process the relevant information, which is vital for effective learning. Thus, on the other hand, we provide a competing hypothesis:

Hypothesis $2 \boldsymbol{b}$. A high level of situational variation in a simulation-based training will lead to less innovation knowledge compared to a low level of situational variation.

Finally, we also examine whether prior innovation knowledge moderates the effect of variation level. Prior knowledge may provide an advantage to learners as it can support the germane load induced by the training, thereby facilitating learning because it requires less mental effort during the training. Also, prior knowledge may lower intrinsic load and extraneous load because learners with prior knowledge understand the provided situations (due to existing mental models). This makes it easier to process the varying information offered in the situations and helps learners avoid distracting stimuli during training. These reductions in cognitive load may increase mental capacity in the working memory to optimize the learning process. Accordingly, we expect that learners with adequate prior innovation knowledge may benefit more from a high level of variation due to their 
ability to filter the provided information. Thus, we hypothesize:

Hypothesis 3. Learners' prior innovation knowledge will moderate the effect of variation level (i.e., low versus high) on innovation knowledge. Learners with high prior knowledge will benefit from high situational variation more than learners with low prior innovation knowledge.

\section{Methods}

\section{Procedure and Sample}

Figure 1 Here

\section{Sample}

This research included 131 students (45.9\% male, $54.1 \%$ female) enrolled in a business and management program at a Belgian university. Participants ranged from 19 to 29 years of age $(M=21$, $\mathrm{SD}=2)$. The majority held a secondary degree $(88.8 \%), 10.4 \%$ bachelor's degree, and $1 \%$ doctoral degree. A sizeable number of participants did not participate in later phases of the study, which is common for multi-week online training settings (Brown, 2001). Table 1 shows the final sample size per condition for each study phase after attrition. Of the original 131 participants, $63 \%$ performed the first post-test at Time 3 (48 hours later), and 44\% performed the second post-test at Time 4 (4 weeks later). This research has been conducted following the ethical requirements established by the Belgian national board of ethics. There was no financial or course-related incentives; participation was voluntary. Students were informed they could stop participating at any time.

\section{Research Protocol}

The study involved four phases administered online via e-mail invitations, see Figure 1. Phase 1 included a pre-test for all participants. Two weeks later in phase two, participants in the experimental condition received a link to the training. In phase 3 a first post-test was given to all participants. Two weeks later in phase 4 a second pots-test was given to all participants.

\section{Control Group}

The control group completed the pre-test and both post-tests but did not receive any training. 


\section{Methods of analysis}

We performed one-way analyses of variance (ANOVAs) and chi-square tests to measure the effect of attrition on the different study conditions with regard to demographic characteristics, performance scores for training motivation, and prior innovation knowledge at Time 1 . We found no significant differences due to attrition (all $p>.05$ ). In addition, participants who only completed the pre-test at Time 1 were excluded from further analysis on the basis of missing data.

We also performed one-way ANOVAs and chi-square tests to identify pre-training (Time 1) differences across conditions for age, gender, level of education, training motivation, or prior innovation knowledge (all $p>.05$ ). None of the analyses showed significant results, indicating that random assignment was effective for ensuring the three groups were similar before training.

Table 1 Here

\section{Intervention}

\section{Training}

The simulation training consisted of situations mimicking real-life innovation challenges. The steps of the training are depicted in Figure 2. Participants were instructed to write the actions they would take to successfully solve the innovation situation, and to explain the effectiveness of their approach. Next, participants received seven possible response actions and were required to rate the effectiveness of each action on a seven-point scale. Additionally, participants received automatic feedback on the different actions. This feedback included the effectiveness ratings for each action given by innovation experts. These expert ratings were displayed next to the effectiveness ratings the participant had given to each action. In the subsequent step, participants were presented with a comprehensive and structured expert model. Participants were then instructed to compare their own solution with the expert model by describing the similarities and differences. Participants were only allowed to proceed to the next situation after writing a minimum of 100 characters. For each of the six 
simulated innovation situations, the same procedure was repeated. In addition, as an attention check, participants were required to answer a multiple-choice question about the feedback provided for each situation.

Figure 2 Here

\section{Instrument}

The innovation situations were developed by two researchers (including the first author of this study) following the protocol for situational judgment test situation development via an inductive approach (Lievens, Peeters, \& Schollaert, 2008; Lievens \& Anseel, 2007). For the purposes of this study, nine situations of the initial 70 were selected (i.e., six for simulation training and three for performance measures). These situations captured innovation challenges such as selecting innovative ideas, gathering support to further implement ideas, managing production complications, and communication issues with clients. Moreover, to ensure the realism of the simulation task, the situations were supplemented with audio, graphics, and interactive activities. Appendix A provides images of a situation used in the simulation task.

Response actions and feedback materials. Response actions were provided to the participants for each situation in the second step of the simulation training. To generate response actions, an inductive method was applied during the developmental stage of the training. We invited 23 innovation experts1 and 18 laypeople 2 to generate responses to each situation, which varied in effectiveness. To further develop the expert-based feedback materials (i.e., the scoring scale of the effectiveness ratings), the gathered actions were evaluated by another 23 innovation experts, and each action was rated by eight of these experts on a seven-point effectiveness scale. Subsequently, the

1All 56 innovation experts held managerial positions in different organizations with 10+ years of experience in the innovation domain. All were part of the network of a Belgian innovation consultancy firm we collaborated with. Examples of job functions: R\&D Director, Innovation Manager, Director of Knowledge, Processes, \& Innovation, R\&D Leader, Senior Manager of New Business Development.

2The laypeople were graduate students that had no business background, such as history, arts and language students. They were novices without any experience or previous training in innovation projects. They were informally recruited through the network of the authors. 
effectiveness of each action was determined by calculating its average rating. After computing the degree of agreement between the raters using intra-class coefficients (ICC), when there was no reasonable level of agreement between the experts the action was excluded (i.e., ICC $<.80$ ).

Development expert models. As part of the training, participants received experts' models as guiding materials for the learning process. An expert model was generated for each of the innovation situations utilized in the simulation training. For this purpose, we asked 10 additional innovation experts to resolve the nine innovation situations during a structured interview following a think-aloud protocol (Ericsson \& Simon, 1993; Hoffman, Shadbolt, Burton, \& Klein, 1995). All interviews were transcribed. Subsequently, consistent structures and similar information in the experts' solutions were highlighted and aggregated to design a comprehensive and structured expert model for each situation (see Day, Arthur, \& Getmann, 2001). Each expert model yielded: (a) a comprehensive approach to problem solving; i.e., with a sequence of steps showing how the specific innovation situation can be effectively resolved, (b) various innovation principles, such as rules of thumb that are in line with the experts' simplified mental models of the innovation process and are applied when confronted with complex and uncertain situations (Gary \& Wood, 2011), and (c) explanations of why these steps and principles would be effective. The expert models were similar in length and level of detail. Appendix B provides an example of an expert model used in the simulation training.

Situational variation. Situational variation was manipulated, with one group (i.e., low situational variation) receiving a training consisting of three different situations and the other group (i.e., high situational variation) receiving a training consisting of six different situations. We decided on the number of situations to provide based on results from a pilot test where nine situations were given in the training. We observed that participants tended to withdraw halfway through training. Their feedback revealed that they felt the training too long to complete with full attention. Therefore, we decreased the high situational variation group to six situations and used half this number of three situations for our low situational variation. Further justification for this decision is that one situation would have no variation and two is considered very limited (see Gary et al., 2012).

Demographic data. At Time 1 we obtained data about the participants' gender, age, and educational level. 
Training motivation. As a control, participants were asked to complete a training motivation questionnaire (Tharenou, 2001) at Time 1. The scale consisted of seven items such as, "I try to learn as much as I can from Training \& Development programs.” Agreement was indicated on a five-point Likert scale $(1=$ strongly disagree to $5=$ strongly agree $)$. The scale's Cronbach's alpha was .79 .

Innovation knowledge. At Time 1, one simulated innovation situation was used to measure the participants' prior innovation knowledge. For both post-training innovation knowledge tests, another simulated innovation situation was used. One example of a written answer of a participant is: "It is too difficult to solve this problem. I don't have any idea about this. I think we have to change the packages. For example, put first a small package into a big package.", a second example is: "I will get the consumers' attention through questionnaire to know what are their expectations which can be incorporated into the following steps that I will take in improving the toilet paper. An innovative solution to this problem is to re-package our company's toilet paper into smaller sizes and make it more attractive in investing in new shape like rectangle. I will also like to inform my company that one way to make it smaller and attractive is to make the re-packaged and re-designed toilet paper of pocket sizes which can be taken about by everyone with satisfaction. I will also reiterate the importance of publicizing the new toilet paper by advertising the re-packaged product so as to keep the consumers' abreast of the new development on the products. " As reflected by these two examples the participants differed in how they approached the situations and which actions they suggested. These written responses of the participants were scored by two independent raters using a coding scheme. These two raters were graduate students of the psychology department, which were trained in how to score the situations. The coding scheme defined if an effective action was proposed as the solution, if the solution was structured and detailed, if the solution held correct and comprehensive explanations, and quantified how many innovation principles were used. These innovation principles were identified based on the models from the innovation experts and were taught during the simulation training. The maximum score was 20 points.

Participants' scores on the innovation knowledge tests were at Time 1 (pre-test): $M=4.94$, $S D=3.49, I C C=.91, n=131$; Time 3 (post-test 48 hours): $M=5.72, S D=2.71, I C C=.93, n=82$; 
and Time 4 (post-test 4 weeks): $M=7.97, S D=4.77, I C C=.94, n=58$. The inter-rater reliability scores were adequate and in line with previous studies (see Jones, 1981).

Analogical learning. We also measured if participants were able to apply the innovation knowledge they had learned to novel innovation situations. These novel innovation knowledge situations were different at a surface level. However, participants needed to apply the same principles they learned in training to solve them effectively. In other words, we measured if participants were able to discover the analogy between the situations they were trained with and the novel situations and understood that they could analogically apply their learned knowledge. We presented a novel innovation situation to participants at Time 3 and one at Time 4 (Gentner et al., 2003). The same coding schema and methodology from the innovation knowledge measures was used. The mean scores were at Time 3 (post-test 48 hours): $M=7.65, S D=3.48, I C C=.93, n=82$; and Time 4 (posttest 4 weeks): $M=8.02, S D=4.17, I C C=.90, n=58$.

\section{Results}

\section{Descriptive Statistics and Correlations}

Table 2 presents the means, standard deviations, and correlations between the study variables. A significant negative relation was observed between gender and innovation knowledge at Time 3 ( $r$ $=-.21 ; p<.05)$. Prior innovation knowledge had significant positive relationships with innovation knowledge $(r=.23, p<.01)$ and analogical learning $(r=.31, p<.01)$ at Time 3 . Training motivation did not have a significant correlation with innovation knowledge at either post-test (for Time 3, $r=$ $.04, p>.05$; and for Time 4, $r=.20, p>.05$ ). Furthermore, we found that innovation knowledge at Time 3 and Time 4 significantly correlated $(r=.73 ; p<.01)$, and there was also a significant positive correlation for analogical learning between Time 3 and Time $4(r=.50 ; p<.01)$. In addition, innovation knowledge at Time 3 had a moderate positive relation with analogical learning at Time 3 $(r=.60 ; p<.01)$ and Time $4(r=.62 ; p<.01)$, while there was a significant correlation at Time $4(r=$ $.70 ; p>.05)$. 


\section{Test of Hypotheses}

Table 3 shows the means and standard deviations for innovation knowledge and analogical learning for Time 3 and Time 4. First, we conducted ANOVAs with training condition as the independent variable and innovation knowledge and analogical learning as the dependent variables for both Time 3 and Time 4 (Hypothesis 1). For innovation knowledge, we found a significant difference between the three conditions at both Time $3, F(2,79)=5.59, p=.005$ and at Time $4, F(2,55)=3.41$, $p=.04$. There was no significant difference in analogical learning across conditions, neither at Time $3, F(2,80)=1.62, p=.20$ nor at Time $4, F(2,54)=.21, p=.814$.

\section{Table 3 Here}

We proceeded with a contrast test conducted via a General Linear Model-procedure for the dependent variable of innovation knowledge measured at Time 3 and Time 4 to further examine whether there was a difference between the combined mean score of the two training conditions and the mean score of the control condition. Since there was no significant differences between the training conditions for analogical learning, no further analyses were conducted for this outcome.

Innovation knowledge was significantly higher in the training groups compared to the control group for both post-tests. There was a mean increase of $1.51,95 \% C I[.34, .2 .67], p=.01$ for Time 3 and a mean increase of $3.07,95 \% C I[.58,5.54], p=.02$ for Time 4 . Our findings indicate that participants scored significantly higher on the innovation knowledge test immediately and 4 weeks after completing a simulation training when compared to a group that received no training. However, this was not found for analogical learning. In sum, we only found partial support for Hypothesis 1.

Tables 4 and 5 show the results of the Tukey post-hoc tests for innovation knowledge as a dependent variable for Time 3 and Time 4 . These analyses were conducted to compare differences across the three conditions for innovation knowledge to test for the competing Hypotheses $2 \mathrm{a}$ and $2 \mathrm{~b}$. Innovation knowledge mean scores at Time 3 and Time 4 increased from the control group, to the low 
situational variation group, and to the high situational variation group (see Table 3). However, the only significant differences were the mean increase in innovation knowledge at Time 3 comparing the control group and high situational variation group $(2.26,95 \%$ CI [.63, 3.9], $p=.004$; see Table 4) and the mean increase at Time 4 comparing the control group and high situational variation group (3.64, $95 \% C I[.19,7.09], p=.037$; see Table 4). No post-hoc tests on analogical learning were conducted since one-way ANOVAs did not reveal significant differences.

Simulation training with high situational variation was effective in improving innovation knowledge initially and 4 weeks after the training in comparison with a control group that received no training. However, we did not find significant differences between the training condition with low situational variation and the control condition or between the two training conditions with different situational variability (i.e., low vs. high) for either post-test. In summary, we found partial support for Hypothesis 2a suggesting that a high level of situational variation can improve innovation knowledge compared to a control group. So the competing Hypothesis $2 \mathrm{~b}$ was not supported.

Table 4 Here

Hypothesis 3 was tested via multiple regression analyses to examine the interaction effect of situational variation level (i.e., low vs. high) and prior innovation knowledge on the dependent variables of innovation knowledge and analogical learning (controlling for both main effects).

There was no significant moderator effect of prior innovation knowledge, as evidenced by the coefficients of the interaction term for Time $3(b=.29, S E=.27, p=.28)$ and Time $4(b=.69, S E=$ $.51, p=.19)$ for innovation knowledge as the dependent variable. Similarly, when analogical learning was the dependent variable, the coefficients of the interaction term were not significant for Time 3 ( $b$ $=.02, S E=.32, p=.96)$ or Time $4(b=.50, S E=.56, p=.38)$. Consequently, Hypothesis 3 is not supported. 


\section{Discussion}

This study aimed at improving the understanding of an important but underexplored training design characteristic, namely situational variation in simulation training. More specifically, we explored whether a high level of situational variation is more effective than a low level and whether this difference is dependent on the learners' prior knowledge.

First, our results supported that innovation knowledge can be advanced by completing simulation-based training. Participants who received simulation training were better at solving innovation problem situations than those who did not. The learning effect was observed immediately after training and also 4 weeks later. However, participants were not able to apply their knowledge to solve new related situations, neither immediately nor 4 weeks after training. A possible explanation might be that the small sample sizes (partly caused by participant attrition) prevented the detection of differences for analogical learning. Another explanation might be that it is difficult to train a complex cognitive outcome such as innovation knowledge when only providing artificial situations. Others have suggested that learners might not incorporate relevant information into their knowledge structures due to a lack of verbalization of what is processed during simulation training (Leemkuil \& de Jong, 2011; Wouters, Paas, \& van Merriënboer, 2008), and this hinders its application in new situations. Thus, we can assume that simulation tasks should ideally be part of a broader training context (Sitzmann, 2011; Wouter \& van Oostendorp, 2017) with supplemental instructions (e.g., a debriefing possibility in which learners can discuss their learned insights).

Second, our findings suggest that only simulation training with an extensive set of varying innovation process situations yielded a significant increase in innovation knowledge compared to a control group. However, no significant differences for analogical learning were found (i.e., participants were unable to apply learned innovation knowledge to new and unfamiliar innovation situations). This seems contrary to the findings of Gary et al. (2012) who reported positive effects by adding only one situation to improve strategic decision making. However, our findings suggest that no cognitive overload of the working memory was induced. Greater variability did not hamper learning but rather improved innovation knowledge. Thus, it can be assumed that more opportunities to practice supported the germane load produced by the training and led to cognitive learning. The 
results also suggest that the higher level of situational variation did not produce a higher level of intrinsic load; training with more variability was not too complex to impede innovation knowledge, as otherwise no learning would have occurred. Of the two possibilities we investigated, we found more evidence supporting the effectiveness of using a higher level of situational variation.

Third, further drawing on theories of mental model formation (Moreno \& Mayer, 2005) and cognitive load theory (Sweller, 1988), we expected that prior knowledge would play a moderating role. Participants with low and high levels of prior knowledge would benefit more from receiving training with low and high variability, respectively. Our results did not support this hypothesis. Prior knowledge did not seem to influence the optimal number of situations during training. However, given that our sample only consisted of students with no prior experience of making decisions or leading organizational innovation projects, we did not detect significant variance in prior innovation knowledge $(M=4.94, S D=3.49)$. This minimal variance in prior knowledge, combined with our small sample size, is a probable explanation for why we did not observe a moderating effect of prior knowledge. Future research could investigate the moderating role of prior knowledge on the level of variability in improving cognitive outcomes, with a sample containing differing degrees of expertise (e.g., experts, novices, and naïves).

\section{Practical Implications}

Our study has direct implications for the design of simulation-based training for cognitive outcomes. Given that organizations prefer efficient employee training, it would be beneficial if training designers focus on developing simulation-based training that enables participants to transfer knowledge and skills they learn into different context. In order to attain this goal, we recommend developing and implementing more extensive training designs with multiple situations that have variable surface characteristics but the same underlying structure. Irrespective of prior participant knowledge, this is a better format than presenting a smaller variety of situations. This should help build a broader knowledge foundation in learners, which can improve their understanding and performance. This recommendation aligns well with a recent meta-analysis for leadership training. Lacerenza, Reyes, Marlow, Joseph, and Salas (2017) demonstrated that longer training duration (i.e., more extensive training) was more effective to train leadership skills; however, caution is needed. In 
our pilot test, participants tended to drop out when we utilized a training with nine situations. This indicates that simulation developers need to strike a balance between variation and brevity. Therefore, we would recommend incorporating an option for the learner to control when to pause and continue the training. This is supported by previous research suggesting integrating learner control into simulation training designs (Landers \& Reddock, 2017) to prevent learners from becoming demotivated by feeling overwhelmed.

\section{Limitations of the Present Study}

Our results should be evaluated in the light of some limitations. First, we did not measure the underlying theoretical mechanisms of mental model formation (i.e., the cognitive processes of selecting, organizing, and integrating) or cognitive load experienced by the learners. Second, only students participated. We should be cautious in generalizing these findings to a business or organizational context. Third, there was attrition for both post-tests resulting in a smaller sample than expected. Although we took multiple actions to counter attrition (e.g., professors emphasized the importance of participation, a motivational information brochure was sent prior to the program start, and multiple reminder emails were sent), a sizeable number of participants still dropped out. A possible explanation is that the program was time intensive, so participants were less motivated to complete the post-tests. Also, encountering technical difficulties (e.g., slow internet, error notifications, etc.) during online training results in higher attrition levels (Sitzmann, Ely, Bell, \& Bauer, 2010). Despite this, training conditions were still comparable regarding gender, age, training motivation, and prior knowledge. A final shortcoming of the study is that due to the online learning context, we had limited control regarding how, where, and when participants completed the different study phases, which may have decreased internal validity. We tried to counter lack of control by emphasizing that participants were required to complete the different phases at a location where it was quiet and they were not distracted. However, as there is no clarity on the impact of the real-life learning environment when learning via a simulation training, further research is needed to specify how this influences the learning process. 


\section{Suggestions for Future Research}

Future research should explore the underlying cognitive mechanisms influencing learning processes during simulation-based training. For instance, by applying recent technologies such as eye tracking, researchers could clarify which information learners focus on during training (Gegenfurtner \& Seppänen, 2013). Including a cognitive load measure would also help to understand how much cognitive load the training produces and how this impacts learning. This would clarify the impact of cognitive load and attention span during training.

To better comprehend the impact of situational variation, it may help to explore a curvilinear relation of situational variation and learning effectiveness. Too little variation is not beneficial, but our pilot study suggests that excessive variation is also not ideal. For this purpose, a study with more levels of situational variation should be carried out.

Another underexplored simulation characteristic that might impact the participants' experience is the role they are required to adopt in different situations. In other words, the perspective from which the participant is involved in the situation. In typical business simulations, participants are often required to take on the role of an employee or manager. For the purpose of developing a richer and broader mental model, it might be interesting to let participants solve situations from the perspectives of different stakeholders and adopt multiple roles. Rather than changing the context, the decision-making role can vary the perspective of the situation and thus the knowledge structures may be expanded.

An additional avenue for future research could be examining the option of micro-training formats (De Jans, Van Geit, Cauberghe, Hudders, \& De Veirman, 2017; Lukosch, Kurapati, Groen, \& Verbraeck, 2016) to advance cognitive learning outcomes. As we observed during our pilot study, participants tend to drop out when they find the training too time and attention intensive. One way to solve this may be to provide different situations separately over a longer timespan instead of offering them during a single session, in essence a micro-training format. This option could reduce the likelihood of cognitive overload of the working memory since only one situation would need to be solved at a given time. 


\section{Conclusion}

A growing body of evidence suggests that simulation-based training can be effective for a variety of learning outcomes, sometimes outperforming traditional learning settings (Gegenfurtner, Quesada-Pallares, \& Knogler, 2014; Sitzmann, 2011; Vogel et al., 2006). Due to its appealing design characteristics and their potential for deeply engaging learners, simulation-based training has become a popular method to improve cognitive outcomes. Organizations seeking to develop effective simulations are often confronted with various design question, for which evidence-based guidelines are not yet available. The current study provides a first answer to a very basic, but important design question: Does situational variation in training simulation make a difference in learning effectiveness? Using an experimental design, we show that high situational variation during a simulation training improved complex cognitive outcomes such as innovation knowledge, irrespective of the learners' prior knowledge about innovation. This finding provides a first step towards a more nuanced understanding of how design characteristics may influence learning through simulation. 


\section{References}

Anderson, J. R. (1982). Acquisition of cognitive skill. Psychological Review, 89(4), 369-406. doi:10.1037//0033-295x.89.4.369

Anderson, N., De Dreu, C. K., \& Nijstad, B. A. (2004). The routinization of innovation research: A constructively critical review of the state-of-the-science. Journal of Organizational Behavior, 25(2), 147-173. doi:10.1002/job.236

Anderson, N., Potočnik, K., \& Zhou, J. (2014). Innovation and creativity in organizations: A state-ofthe-science review, prospective commentary, and guiding framework. Journal of Management, 40(5), 1297-1333. doi:10.1177/0149206314527128

Anderson, P. H., \& Lawton, L. (2009). Business simulations and cognitive learning: Developments, desires, and future directions. Simulation \& Gaming, 40(2), 193-216. doi:10.1177/1046878108321624

Arthur Jr., W., Bennett, W., Edens, P. S., \& Bell, S. T. (2003). Effectiveness of training in organizations: A meta-analysis of design and evaluation features. Journal of Applied Psychology, 88(2), 234-245. doi:10.1037/0021-9010.88.2.234

Baddeley, A. (1992). Working memory. Science, 255(5044), 556-559. doi:10.1126/science.1736359

Baddeley, A. (2003). Working memory: Looking back and looking forward. Nature Reviews Neuroscience, 4(10), 829-839. doi:10.1038/nrn1201

Bandura, A. (1977). Social Learning Theory. Englewood-Cliffs, NJ: Prentice Hall.

Beal, S. A., \& Christ, R. E. (2004). Training effectiveness evaluation of the Full Spectrum Command game (Tech. Rep. No. 1140). Arlington, VA: US Army Research Institute for the Behavioral and Social Sciences.

Bedwell, W. L., Pavlas, D., Heyne, K., Lazzara, E. H., \& Salas, E. (2012). Toward a taxonomy linking game attributes to learning an empirical study. Simulation \& Gaming, 43(6), 729-760. doi:10.1177/1046878112439444

Bell, B. S., Kanar, A. M., \& Kozlowski, S. W. J. (2008). Current issues and future directions in simulation-based training in North America. International Journal of Human Resource Management, 19(8), 1416-1434. doi:10.1080/09585190802200173 
Birdi, K., Leach, D., \& Magadley, W. (2016). Factors influencing innovative behavior. Journal of Product Innovation Management, 33, 19-35. doi:10.1111/jpim.12250

Bouhnik, D., \& Marcus, T. (2006). Interaction in distance-learning courses. Journal of the American Society for Information Science and Technology, 57(3), 299-305. doi:10.1002/asi.20277

Brown, K. G. (2001). Using computers to deliver training: Which employees learn and why? Personnel Psychology, 54(2), 271-296. doi:10.1111/j.1744-6570.2001.tb00093.x

Cannon-Bowers, J. \& Bowers, C. (2009). Synthetic learning environments: On developing a science of simulation, games, and virtual worlds for training. In S.W. J. Kozlowski and E. Salas (Eds.), Learning, Training, and Development in Organizations (pp. 229-263). New York: Routledge.

Cannon-Bowers, J. A., Bowers, C., \& Procci, K. (2010). Optimizing learning in surgical simulations: Guidelines from the science of learning and human performance. Surgical Clinics of North America, 90(3), 583-603. doi:10.1016/j.suc.2010.02.006

Chi, M. T. H., Feltovich, P. J., \& Glaser, R. (1981). Categorization and representation of physics problems by experts and novices. Cognitive Science, 5(2), 121-152. doi:10.1207/s15516709cog0502_2

Cook, M. P. (2006). Visual representations in science education: The influence of prior knowledge and cognitive load theory on instructional design principles. Science Education, 90(6), 10731091. doi:10.1002/sce.20164

Consorti, F., Mancuso, R., Nocioni, M., \& Piccolo, A. (2012). Efficacy of virtual patients in medical education: A meta-analysis of randomized studies. Computers \& Education, 59(3), 10011008. doi:10.1016/j.compedu.2012.04.017

Dane, E., \& Pratt, M. G. (2007). Exploring intuition and its role in managerial decision making. Academy of Management Review, 32(1), 33-54. doi:10.5465/amr.2007.23463682

Dane, E., Rockmann, K. W., \& Pratt, M. G. (2012). When should I trust my gut? Linking domain expertise to intuitive decision-making effectiveness. Organizational Behavior and Human Decision Processes, 119(2), 187-194. 
De Jans, S., Van Geit, K., Cauberghe, V., Hudders, L., \& De Veirman, M. (2017). Using games to raise awareness: How to co-design serious mini-games? Computers \& Education, 110, 77-87. doi:10.1016/j.compedu.2017.03.009

Dochy, F. (1994). Prior knowledge and learning. In T. Husen \& T.N. Postlethwaite (Eds.), International Encyclopedia of Education (pp. 4698-4702). Oxford, UK: Pergamon Press.

Dochy, F., Segers, M., \& Buehl, M. M. (1999). The relation between assessment practices and outcomes of studies: The case of research on prior knowledge. Review of Educational Research, 69(2), 145-186. doi:10.3102/00346543069002145

Ellis, R. A., Marcus, G., \& Taylor, R. (2005). Learning through inquiry: student difficulties with online course-based material. Journal of Computer Assisted Learning, 21(4), 239-252. doi:10.1111/j.1365-2729.2005.00131.x

Feldon, D. F. (2007). Cognitive load and classroom teaching: The double-edged sword of automaticity. Educational Psychologist, 42(3), 123-137. doi:10.1080/00461520701416173

Garris, R., Ahlers, R., \& Driskell, J. E. (2002). Games, motivation, and learning: A research and practice model. Simulation \& Gaming, 33(4), 441-467. doi:10.1177/1046878102238607

Gary, M. S., \& Wood, R. E. (2011). Mental models, decision rules, and performance heterogeneity. Strategic Management Journal, 32(6), 569-594. doi:10.1002/smj.899

Gary, M. S., Wood, R. E., \& Pillinger, T. (2012). Enhancing mental models, analogical transfer, and performance in strategic decision making. Strategic Management Journal, 33(11), 1229-1246. doi:10.1002/smj.1979

Gavetti, G., \& Levinthal, D. (2000). Looking forward and looking backward: Cognitive and experiential search. Administrative Science Quarterly, 45(1), 113-137. doi:10.2307/2666981

Gathercole, S. E., \& Alloway, T. P. (2008). Working memory and learning: A practical guide for teachers. Thousand Oaks, CA: SAGE Publications.

Gegenfurtner, A., Quesada-Pallares, C., \& Knogler, M. (2014). Digital simulation-based training: A meta-analysis. British Journal of Educational Technology, 45(6), 1097-1114. doi:10.1111/bjet.12188 
Gegenfurtner, A., \& Seppänen, M. (2013). Transfer of expertise: An eye tracking and think aloud study using dynamic medical visualizations. Computers \& Education, 63, 393-403. doi:10.1016/j.compedu.2012.12.021

Gentner, D., Loewenstein, J., \& Thompson, L. (2003). Learning and transfer: A general role for analogical encoding. Journal of Educational Psychology, 95(2), 393-408. doi:10.1037/00220663.95.2.393

Gentner, D., \& Stevens, A. L. (Eds.). (1983). Mental Models. Hillsdale, NJ: Lawrence Erlbaum. Gosen, J., \& Washbush, J. (2004). A review of scholarship on assessing experiential learning effectiveness. Simulation \& Gaming, 35(2), 270-293. https://doi.org/10.1177/1046878104263544

Johnson-Laird, P. N. (1983). Mental models: Towards a cognitive science of language, inference, and consciousness. Cambridge, MA: Harvard University Press.

Jones, A. (1981). Inter-rater reliability in the assessment of group exercises at a UK assessment centre. Journal of Occupational Psychology, 54(2),79-86. doi:10.1111/j.20448325.1981.tb00046.x

Kozlowski, S. W. J., \& Bell, B. S. (2007). A theory-based approach for designing distributed learning systems. In S. M. Fiore and E. Salas (Eds.), Toward a Science of Distributed Learning (pp. 15-39). Washington, DC: APA.

Kraiger, K., Ford, J. K., \& Salas, E. (1993). Application of cognitive, skill-based, and affective theories of learning outcomes to new methods of training evaluation. Journal of Applied Psychology, 78(2), 311-328. doi:10.1037/0021-9010.78.2.311

Lacerenza, C. N., Reyes, D. L., Marlow, S. L., Joseph, D. L., \& Salas, E. (2017). Leadership training design, delivery, and implementation: A meta-analysis. Journal of Applied Psychology, 102(12), 1686-1718. doi:10.1037/ap10000241

Lainema, T., \& Nurmi, S. (2006). Applying an authentic, dynamic learning environment in real world business. Computers \& Education, 47(1), 94-115. doi:10.1016/j.compedu.2004.10.002 
Landers, R. N., \& Reddock, C. M. (2017). A meta-analytic investigation of objective learner control in web-based instruction. Journal of Business and Psychology, 32(4), 455-478. doi:10.1007/s10869-016-9452-y

Leemkuil, H., \& Jong, T. D. (2011). Instructional support in games. In S. Tobias and J. D. Fletcher (Eds.), Computer Games and Instruction (pp. 353-369). Charlotte, NC: IAP Information Age Publishing.

Liaw, S. S. (2008). Investigating students' perceived satisfaction, behavioral intention, and effectiveness of e-learning: A case study of the Blackboard system. Computers \& Education, 51(2), 864-873. doi:10.1016/j.compedu.2007.09.005

Lovelace, K. J., Eggers, F., \& Dyck, L. R. (2016). I do and I understand: Assessing the utility of webbased management simulations to develop critical thinking skills. Academy of Management Learning \& Education, 15(1), 100-121. doi:10.5465/amle.2013.0203

Lukosch, H., Kurapati, S., Groen, D., \& Verbraeck, A. (2016). Microgames for situated learning: A case study in interdependent planning. Simulation \& Gaming, 47(3), 346-367. doi:10.1177/1046878116635468

Mayer, B. W., Dale, K. M., Fraccastoro, K. A., \& Moss, G. (2011). Improving transfer of learning: Relationship to methods of using business simulation. Simulation \& Gaming, 42(1), 64-84. doi:10.1177/1046878110376795

Mayer, R. E. (2011). Applying the science of learning to multimedia instruction. In J. P. Mestre and B. H. Ross (Eds.), Psychology of Learning and Motivation, 55 (pp. 77-108). San Diego, CA: Elsevier Academic Press. doi:10.1016/B978-0-12-387691-1.00003-X

Moreno R., \& Mayer R. E. (2005). Role of guidance, reflection, and interactivity in an agent-based multimedia game. Journal of Educational Psychology, 97(1), 117-128. doi:10.1037/00220663.97.1.117

Ong, C. S., \& Lai, J. Y. (2006). Gender differences in perceptions and relationships among dominants of e-learning acceptance. Computers in Human Behavior, 22(5), 816-829. doi:10.1016/j.chb.2004.03.006 
Paas, F., Renkl, A., \& Sweller, J. (2003). Cognitive load theory and instructional design: Recent developments. Educational Psychologist, 38(1), 1-4. ～doi:10.1207/s15326985ep3801_1

Paas, F., \& van Merriënboer, J. J. G. (1994). Variability of worked examples and transfer of geometrical problem-solving skills - A cognitive-load apporach. Journal of Educational Psychology, 86(1), 122-133. doi:10.1037/0022-0663.86.1.122

Palmunen, L. M., Pelto, E., Paalumäki, A., \& Lainema, T. (2013). Formation of novice business students' mental models through simulation gaming. Simulation \& Gaming, 44(6), 846-868. doi:10.1177/1046878113513532

Parchman, S. W., Ellis, J. A., Christinaz, D., \& Vogel, M. (2000). An evaluation of three computerbased instructional strategies in basic electricity and electronics training. Military Psychology, 12(1), 73-87. doi:10.1207/S15327876MP1201_4

Polanyi, M. (1966). The Tacit Dimension. Gloucester, MA: Peter Smith.

Rogers, L. (2011). Developing simulations in multi-user virtual environments to enhance healthcare education. British Journal of Educational Technology, 42(4), 608-615. doi:10.1111/j.14678535.2010.01057.x

Rutten, N., Van Joolingen, W. R., \& Van Der Veen, J. T. (2012). The learning effects of computer simulations in science education. Computers \& Education, 58(1), 136-153. doi:10.1016/j.compedu.2011.07.017

Sanchez, D., \& Van Lysebetten, S. (2017). Findings from a meta-analysis on training games and learning outcomes: Future directions. In M. B. Armstrong (Chair), D. R. Sanchez (Co-Chair), K. N. Bauer (Co-Chair), and K. Kraiger (Discussant), Gaming and Gamification IGNITE: Current Trends in Research and Application. Symposium presented at the 32nd Annual Conference of the Society for Industrial and Organizational Psychology, Orlando, FL.

Salas. E., Wildman J., \& Piccolo, R. (2009). Using simulation-based training to enhance management education. Academy of Management Learning and Education, 8(4), 559-573. doi:10.5465/amle.8.4.zqr559

Scherpereel, C. M. (2005). Changing mental models: Business simulation exercises. Simulation \& Gaming, 36(3), 388-403. doi:10.1177/1046878104270005 
Scott, S. G., \& Bruce, R. A. (1994). Determinants of innovative behavior: A path model of individual innovation in the workplace. Academy of Management Journal, 37(3), 580-607. doi:10.2307/256701

Singley, M. K., \& Anderson, J. R. (1989). The Transfer of Cognitive Skill. Cambridge, MA: Harvard University Press.

Siewiorek, A., Gegenfurtner, A., Lainema, T., Saarinen, E., \& Lehtinen, E. (2013). The effects of computer-simulation game training on participants' opinions on leadership styles. British Journal of Educational Technology, 44(6), 1012-1035. doi:10.1111/bjet.12084

Sitzmann, T. (2011). A meta-analytic examination of the instructional effectiveness of computerbased simulation games. Personnel Psychology, 64(2), 489-528. doi:10.1111/j.17446570.2011.01190.x

Sitzmann, T., Ely, K., Bell, B. S., \& Bauer, K. (2010). The effects of technical difficulties on learning and attrition during online training. Journal of Experimental Psychology: Applied, 16(3), 281292. doi:10.1037/a0019968

Sun, P. C., Tsai, R. J., Finger, G., Chen, Y. Y., \& Yeh, D. (2008). What drives a successful eLearning? An empirical investigation of the critical factors influencing learner satisfaction. Computers \& Education, 50(4), 1183-1202. doi:10.1016/j.compedu.2006.11.007

Sweller, J. (1988). Cognitive load during problem solving: Effects on learning. Cognitive Science, 12(2), 257-285. doi:10.1207/s15516709cog1202_4

Sweller, J. (2010). Element interactivity and intrinsic, extraneous, and germane cognitive load. Educational Psychology Review, 22(2), 123-138. doi:10.1007/s10648-010-9128-5

Van Gerven, P. W. M., Paas, F., van Meriënboer, J. J. G., \& Schmidt, H. G. (2006). Modality and variability as factors in training the elderly. Applied Cognitive Psychology, 20(3), 311-320. doi:10.1002/acp.1247

van Gog, T., Paas, F., \& Sweller, J. (2010). Cognitive load theory: Advances in research on worked examples, animations, and cognitive load measurement. Educational Psychology Review, 22(4), 375-378. doi:10.1007/s10648-010-9145-4 
van Merriënboer, J. J. G., Kester, L., \& Paas, F. (2006). Teaching complex rather than simple tasks: Balancing intrinsic and germane load to enhance transfer of learning. Applied Cognitive Psychology, 20(3), 343-352. doi:10.1002/acp.1250

Vogel, J. J., Vogel, D. S., Cannon-Bowers, J., Bowers, C. A., Muse, K., \& Wright, M. (2006). Computer gaming and interactive simulations for learning: A meta-analysis. Journal of Educational Computing Research, 34(3), 229-243. doi:10.2190/FLHV-K4WA-WPVQHOYM

Wagner, R. K. (1987). Tacit knowledge in everyday intelligent behavior. Journal of Personality and Social Psychology, 52(6), 1236-1241. doi:10.1037//0022-3514.52.6.1236

West, M. A., \& Farr, J. L. (1990). Innovation at work. In M. A. West \& J. Farr (Eds.), Innovation and Creativity at Work (pp. 3-13). Chichester, UK: Wiley

Wouters P., \& van Oostendorp, H. (2017) Overview of Instructional Techniques to Facilitate Learning and Motivation of Serious Games. In P. Wouters \& H. van Oostendorp (Eds.), Instructional Techniques to Facilitate Learning and Motivation of Serious Games. Advances in GameBased Learning (pp. 1-16). New York, NY: Springer.

Wouters, P., Paas, F., \& van Merriënboer, J. J. M. (2008). How to optimize learning from animated models: A review of guidelines base on cognitive load. Review of Educational Research, 78, 645-675. doi:10.3102/ 0034654308320320

Yuan, F., \& Woodman, R. W. (2010). Innovative behavior in the workplace: The role of performance and image outcome expectations. Academy of Management Journal, 53, 323-342. https://doi.org/10.5465/amj.2010.49388995 
Figure 1. Study Overview

\begin{tabular}{|c|c|c|c|c|c|c|}
\hline $\begin{array}{l}\text { Time } 1 \\
\text { Pre-test }\end{array}$ & 2 weeks & $\begin{array}{c}\text { Time } 2 \\
\text { Manipulation }\end{array}$ & 48 hours & $\begin{array}{l}\text { Time } 3 \\
\text { Post-test }\end{array}$ & 4 weeks & $\begin{array}{c}\text { Time } 4 \\
\text { Post-test }\end{array}$ \\
\hline 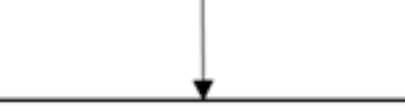 & & 3 Conditions & & 7 & & \\
\hline $\begin{array}{l}\text { - } \quad \text { Demographic } \\
\text { Variables }\end{array}$ & & $\begin{array}{c}\text { Control Group without } \\
\text { Training }\end{array}$ & & $\begin{array}{l}\text { - Innovation } \\
\text { Knowledge }\end{array}$ & & $\begin{array}{l}\text { - } \quad \text { Innovation } \\
\text { Knowledge }\end{array}$ \\
\hline $\begin{array}{ll}\text { - } & \text { Training } \\
\text { Motivation } \\
\text { - } & \text { Prior Knowledge }\end{array}$ & & $\begin{array}{c}\text { 1st Experimental Group } \\
\text { (Low Situational } \\
\text { Variation Training) }\end{array}$ & & $\begin{array}{l}\text { - Analogical } \\
\text { Learning }\end{array}$ & & $\begin{array}{l}\text { - } \quad \text { Analogical } \\
\text { Learning }\end{array}$ \\
\hline & & $\begin{array}{c}\text { 2nd Experimental } \\
\text { Group (High Situational } \\
\text { Variation Training) }\end{array}$ & & & & \\
\hline
\end{tabular}




\section{Following sequence is repeated for each situation during the training:}

Step 1: Participants are asked to provide actions to solve the simulated innovation situation and give an explanation for the chosen approach.

Step 2: Participants are required to rate seven response action options on a sevenpoint effectiveness scale.

Step 3: Participants receive automatic feedback on how they rated each response action and can compare their scoring with those of innovation experts.

Step 4: Participants receive a comprehensive and structured expert model that gives a clear overview of different actions and provides explanations of why each action is beneficial.

\footnotetext{
Step 5: Participants are instructed to actively compare their own solution approach with the expert model by describing the similarities and differences. In this manner they actively process the correct expert models.
} 
5 Table 1

$6 \quad$ Final sample distribution by condition at each time

\begin{tabular}{lcccc}
\hline Condition & Time 1 & Time 2 & Time 3 & Time 4 \\
\hline $\begin{array}{l}\text { Control } \\
\text { Experimental }\end{array}$ & 43 & -- & 31 & 22 \\
Low SV & 46 & 37 & 25 & 17 \\
$\begin{array}{l}\text { Experimental } \\
\text { High SV }\end{array}$ & 42 & 33 & 26 & 19 \\
Total $n$ & 131 & 70 & 82 & 58 \\
\hline
\end{tabular}

$7 \quad$ Note. SV $=$ Situational Variation Training 
$9 \quad$ Means, standard deviations, and correlations

\begin{tabular}{|c|c|c|c|c|c|c|c|c|c|}
\hline & $M$ & $S D$ & 1 & 2 & 3 & 4 & 5 & 6 & 7 \\
\hline 1. Gender & $--\mathrm{a}$ & $--\mathrm{a}$ & -- & & & & & & \\
\hline 2. Age & 21.04 & 1.74 & $-.41 * *$ & - & & & & & \\
\hline 3. Training Motivation & 3.90 & 0.39 & .10 & -.07 & - & & & & \\
\hline 4. Prior Knowledge & 4.94 & 3.49 & -.01 & .11 & -.04 & - & & & \\
\hline 5. Innovation Knowledge (T3) & 5.72 & 2.71 & $-.21 *$ & -.05 & .04 & $.23 *$ & - & & \\
\hline 6. Innovation Knowledge (T4) & 7.97 & 4.77 & -.01 & -.03 & .20 & .15 & $.73 * *$ & -- & \\
\hline 7. Analogical Learning (T3) & 7.65 & 3.48 & .20 & .10 & .16 & $.31 * *$ & $.60 * *$ & $.56 * *$ & - \\
\hline 8. Analogical Learning (T4) & 8.02 & 4.17 & -.16 & -.04 & .05 & .21 & $.62 * *$ & $.70^{* * *}$ & $.50 * *$ \\
\hline
\end{tabular}

10 Note. Gender: $0=$ male, $1=$ female. $\mathrm{T} 3=$ Time 3 ; $\mathrm{T} 4=$ Time 4 .

11 aMeans and SDs could not be calculated since they are categorical variables.

$12 * p<.05, * * p<.01$ 
14 Means and standard deviations for cognitive outcome tests by condition

\begin{tabular}{|c|c|c|c|c|c|c|c|c|}
\hline \multirow[b]{3}{*}{ Condition } & \multicolumn{4}{|c|}{ Innovation Knowledge } & \multicolumn{4}{|c|}{ Analogical Learning } \\
\hline & \multicolumn{2}{|c|}{$\mathrm{T} 3$} & \multicolumn{2}{|c|}{$\mathrm{T} 4$} & \multicolumn{2}{|c|}{$\mathrm{T} 3$} & \multicolumn{2}{|c|}{$\mathrm{T} 4$} \\
\hline & $M$ & $S D$ & $M$ & $S D$ & $M$ & $S D$ & $M$ & $S D$ \\
\hline Control & 4.77 & 1.80 & 6.05 & 4.82 & 6.77 & 3.23 & 7.77 & 3.02 \\
\hline Experimental Low SV & 5.52 & 2.68 & 8.53 & 4.95 & 8.31 & 3.79 & 7.75 & 5.25 \\
\hline Experimental High SV & 7.04 & 3.03 & 9.68 & 3.87 & 8.00 & 3.27 & 8.53 & 4.48 \\
\hline
\end{tabular}

15 Note. Possible score range 0-20. T3 = Time 3; T4 = Time 4; SV = Situational Variation Training.

$16 \quad$ Table 4

17 Post-hoc Tukey tests (ANOVA) for Innovation Knowledge

\begin{tabular}{lllll}
\hline Condition & Comparison & Mean Difference & Significance & $C I$ \\
\hline Time $3(N=82)$ & & & & \\
Control & Low SV & -0.75 & .53 & $-2.40,0.91$ \\
& High SV & -2.26 & $.004 * *$ & $3.90,0.63$ \\
Low SV & High SV & -1.52 & .10 & $-3.24,0.20$ \\
& & & & \\
Time 4 $(N=58)$ & & & & \\
Control & Low SV & -2.49 & .22 & $-6.04,1.07$ \\
& High SV & -3.64 & $.04 *$ & $-7.09,-0.19$ \\
Low SV & High SV & -1.16 & .73 & $-4.83,2.52$ \\
\hline
\end{tabular}

18 Note. $C I=$ Confidence Interval; $\mathrm{SV}=$ Situational Variation Training.

19 aDifference between the marginal means of the condition and its comparison.

$20 * p<.05 . * p<.01$. 
23 Example Innovation Situation

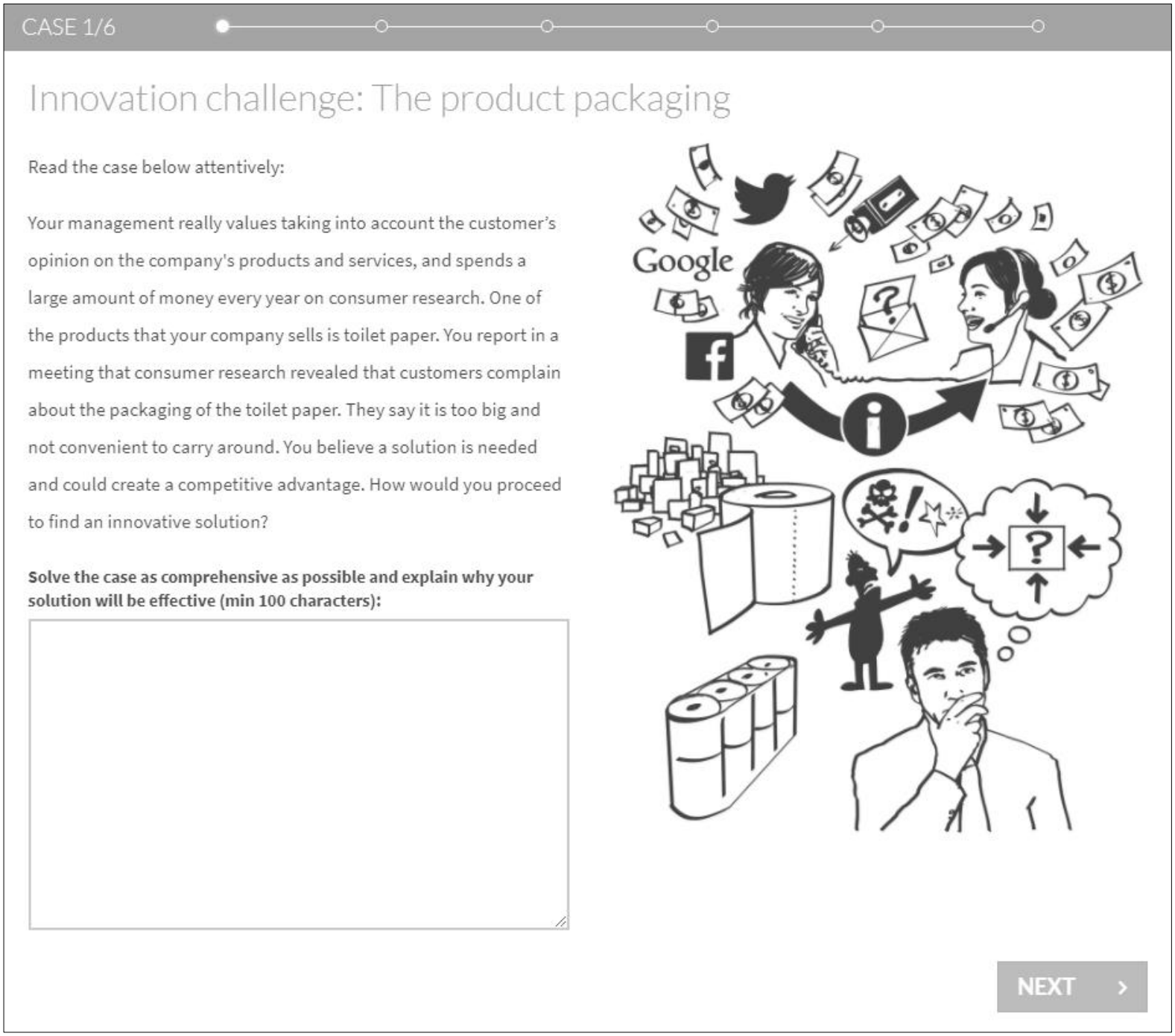




\section{Example Expert Model}

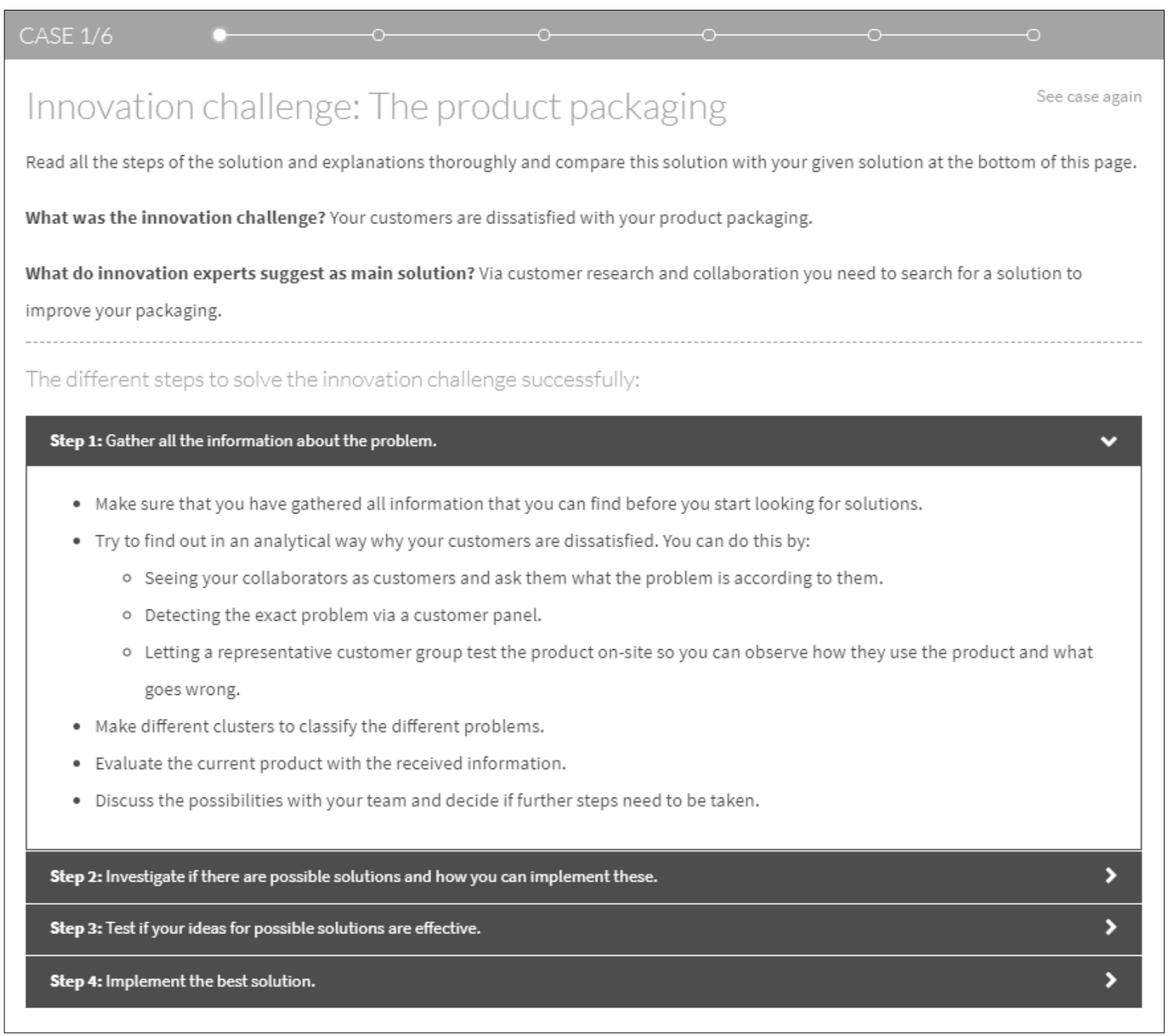

